Research Article

\title{
The Influencing Factors and Promotion Countermeasures of Industrial Generic Technology Diffusion Based on Differential Game
}

\author{
Fenglian Wang $\mathbb{D}^{1},{ }^{1}$ Rongjian Xie $\mathbb{C}^{2},{ }^{2}$ and Wengting $\mathrm{Hu}^{1}$ \\ ${ }^{1}$ School of Economics and Management, Anhui Polytechnic University, Wuhu 241000, China \\ ${ }^{2}$ School of Management, University of Science and Technology of China, Hefei 230000, China \\ Correspondence should be addressed to Rongjian Xie; xierongjian2001@163.com
}

Received 19 December 2020; Revised 9 March 2021; Accepted 16 March 2021; Published 1 April 2021

Academic Editor: Polinpapilinho Katina

Copyright ( $\odot 2021$ Fenglian Wang et al. This is an open access article distributed under the Creative Commons Attribution License, which permits unrestricted use, distribution, and reproduction in any medium, provided the original work is properly cited.

\begin{abstract}
Many factors affect the diffusion of generic technology due to the variety of generic technology and the multiplicity of diffusion carriers. Therefore, it is very urgent to determine the main factors that influence generic technology diffusion. Based on theories of industrial generic technology diffusion, this paper constructs a differential game-based model between government and enterprises. Then, this study explores the key factors that affect the diffusion strategy of industrial generic technology innovation and analyzes the possible method for improving industrial generic technology innovation diffusion. The following conclusions are obtained. Incentive measures, rewards, and penalties play a key role in the diffusion of generic technology, and the costs and benefits incurred by the diffusion are critical to the diffusion of generic technology. Also, the net income of enterprises has a positive impact on the adoption of generic technology diffusion. After that, this paper carries out data simulation for result verification and provides some policy implications.
\end{abstract}

\section{Introduction}

Throughout human history, industrial and agricultural revolutions have exerted great influence on human society and brought major changes to the developing world. However, the development and progress of industry and agriculture depend on the innovation of corresponding technologies and the diffusion of technological innovations. For example, the invention of papermaking and the diffusion of this technology nourished the soil for culture, and the spread of smelting technology improved farming efficiency, and the diffusion of steam engine technology powered the industrial revolution worldwide. Nowadays, the diffusion of generic technology has not only sped up industrial development but also become an important means of promoting industrial upgrading and economic growth. Due to its nonmarket-oriented nature and the similarity, crossover, and integration of a large number of technologies, the industrial generic technology has become a platform technology across industrial sectors, which promotes the progress of other technologies. Besides, the technology has become an important driving force for industrial development and has broad application prospects. In the industrial innovation system, generic technology occupies a central position. It contributes to the technological advancements of the entire industry and plays an important role in industrial upgrading, thus guaranteeing an improvement in industrial and even national competitiveness [1]. At present, China is at a critical stage in its efforts to transform its economic development mode. Whether a breakthrough can be made in industrial generic technology is related to the transformation and upgrading of traditional industrial structure and the effective cultivation of strategic emerging industries [2]. Exploring the factors that affect the diffusion of generic technology and seeking countermeasures to improve generic technology is a major issue today.

According to existing literature, problems such as lack of effective technology diffusion mechanism, weak technology 
supply capacity, vague government role, and lack of generic technology innovation subjects are the major obstacles to China's industrial technological innovation and progress. In recent years, the diffusion of generic technology has been the focus of research, and most of the existing studies were conducted from the following three levels.

1.1. Concepts, Theory, Characteristics, and Components. Zou [3] extended the concept of generic technology. In his view, the diffusion of generic technology was featured with knowledge dissemination, unique network, government intervention, relevance to the form of research and development, and dependence on its form and carrier. Zou [4] believed that the diffusion of generic technology was a systematic process. Through analyzing this complex process, he proposed that the four elements, that is, the social system, government influence, time, and diffusion object constituted the entire diffusion process. Khan et al. [5] believed that the dissemination and adoption of information and communications technology (ICT) were profoundly affected by seven factors, which were social, political, environmental, regulatory, technological, economic, and legal factors separately. Among them, the social and political factors had the greatest impact on ICT dissemination, while the remaining factors seemed to have a moderate impact.

1.2. Influencing Factors. According to various studies, it can be found that the influencing factors of generic technology diffusion are complex and diverse. Based on the 25-year panel data collected from 280 areas in rural India, Zhang et al. [6] pointed out that, in the process of technology dissemination, successful early adopters had more influence on neighboring adopters than failed ones. Song et al. [7] simulated the process of technology diffusion between network organizations and analyzed the influence of the local world characteristics, nodes, evolution, and network structure of the weighted local world network organization on the technology diffusion rate. The research results of Zhou [8] showed that development service synergy, policy intervention support, expected economic benefits, and generic technology readiness were all conducive to the diffusion of generic enabling technologies. Ma et al. [9] believed that, in the adoption of generic technology, the government played a central role, while, in the secondary innovation of generic technology, the government played an intermediary role. However, in the pricing process of generic technology products, the government played a limited role. In the process of choosing the secondary innovation method, compared with the additional benefits, the factor that enterprises need to consider more was the innovation knowledge spillover, and the primary factor influencing accompanying product diffusion was the technical performance of the industrial generic technology. Liu [10] derived the time path function of technology diffusion in low-carbon cities based on the classic technology diffusion model. The research suggested that due to the difference of internal and external factors and the total number of "potential adopters," the time path functions of human resources' cities of different regions were different, and different cities varied in the promotion of technology. Zheng et al. [11] studied the factors that affected the diffusion of generic technology. They believed that if the research and development behavior of enterprises was based on the risk-benefit trade-off of generic technology, the research and development of generic technology would likely fail. Zhang and Ling [12] studied the problems faced by small and medium-sized enterprises (SMEs) in the diffusion of generic technology. They believed that only when the supply mechanism of generic technology evolved from a technology-based type to a demand-oriented type and the generic technology itself showed more attributes of public goods could the level of generic technology diffusion improve. Niu et al. [13] pointed out that the intangible characteristics of services would inevitably lead to the spillover effects of services.

1.3. Diffusion Mechanism. In terms of the diffusion mechanism of generic technology, many scholars have also made great contributions. Tassey [14] proposed a model that overcame the defect of "double failure" in the process of industrial generic technological innovation by decomposing the function of knowledge production into key elements of a specific industrial technology. Zou [15] conducted a systematic analysis of the government's functions in the diffusion of generic technology, and it could be concluded from the study that the government played an irreplaceable role in the diffusion of generic technology. Li [16] summarized the existing typical model practice of generic technology supply and diffusion and proposed to identify the characteristics of generic technology from two dimensions, that is, technology sharing and technology development. And, based on that, the theoretical analysis framework for the selection of a specific model corresponding to the characteristics of generic technology is presented. Wei and Li [17] adopted the technological process theory. For the different stages of the innovation process of industrial generic technology, the innovation decision-making, development, and diffusion stages were used as clues. They believed that, given that government functions were hard to innovate in this process, the government should ensure the innovation of industrial generic technology in a timely and appropriate manner according to the different stages of the innovation process, the government's role in the industrial generic technology innovation, and the scope of intervention, methods, and specific functions. Zhao et al. [18] established a differential game model for technology sharing between civilian and military enterprises in the context of the military-civilian integrated collaborative innovation system. To achieve the optimal benefits, optimal strategies, and overall system benefits of both parties, revenues were calculated separately from the three scenarios of Stackelberg master-slave game, collaborative cooperative game, and Nash noncooperative game. To make the individual income of civil and military enterprises reach the Pareto optimal and the coordinated technology sharing of both parties, they analyzed the results obtained, thus obtaining the value range of the system's overall income distribution coefficient. Zheng et al. [19] 
regarded government support, enterprise adoption, and generic technology supply and their benefits as the driving force, traction, and source power, respectively, and established the diffusion dynamic mechanism of generic technology of these three forces and the interactions between them. On the basis of certain theoretical assumptions, Xia and Deng [20] corresponded the external and internal factors influencing technology diffusion to the government and market functions in the Bass model, respectively, and constructed the functional relationship between them based on the "crowding out" effect of the influence of the government's function on the market's function. They transformed the Bass model based on this functional relationship to enable it to depict the influence of the government's function on the industrial generic technology in terms of time path and diffusion speed. Yang [21] used evolutionary game theory to analyze the evolutionary stability strategy of technology spillover of multinational companies. The result showed that technology spillover was a complex and gradual evolution process, and the result of technology spillover was not only affected by the host country's institutional environment, market environment, and enterprises' absorptive capacity but also depended on the behavior tendency of enterprises and the strategic interaction behavior of both parties.

A review of related references found that most of the existing literature focuses on the key factors of the diffusion of generic technology, the problems they face, and their impacts on economic benefits, while less attention is paid to the corresponding improvement measures for the factors affecting the diffusion of generic technology. Different from the existing literature, this paper sorts out the influencing factors of generic technology diffusion systematically. Based on the game model proposed in the existing papers, the enterprise and the government are used as the two game players to conduct dynamic evolution analysis so as to obtain the factors influencing technology diffusion. Then, data simulation is conducted and some promotion strategies of generic technology diffusion are put forward.

\section{Model Assumptions and Establishment}

According to the related research on generic technology, enterprises play a core role in the $\mathrm{R} \& \mathrm{D}$ process of generic technology and act as the main market of generic technology diffusion, and the government indirectly participates in generic technology diffusion through support and assistance. Without loss of generality, we choose enterprise and government as two generic technology diffusion subjects and put forward the following five assumptions for generic technology diffusion.

Hypothesis 1. In the game of generic technology diffusion, the two most core-related entities of the enterprise and the government are selected as the players of the game, and both parties are determined to be the participants of limited rational behavior, and the players always pursue the maximization of their interests.
Hypothesis 2. Both parties in the game abide by the evolution of natural laws, other external factors will not interfere with the two parties in the game, and win-win cooperation is the common goal of both parties.

Hypothesis 3. To simplify the model, the strategic space for both parties of the generic technology diffusion game is government $G=(g$ policy support, $\bar{g}$ without policy support); enterprise $E=(e$ participates in diffusion, $\bar{e}$ does not participate in diffusion).

Hypothesis 4. The probability of the government providing policy support is $x$; then, the probability of the government not providing policy support is $1-x$. The probability that the enterprise will diffuse the generic technology is $y$; then, the probability that the enterprise will not diffuse the generic technology is $1-y$, and $0 \leq x \leq 1,0 \leq y \leq 1$.

For the government, the special funds for the diffusion of generic technology are $C_{g}$, and when companies participate in the diffusion of generic technology, the technological progress brought about will also bring benefits $V_{g}$ to the government; conversely, when companies do not carry out the diffusion of generic technology, the government will have hidden loss of benefits $P_{g}$ due to lagging development.

For enterprises, the normal production income is $S_{e}$. They intend to introduce capital investment, human and material resources, and other diffusion input cost $C_{e}$ in the process of generic technology diffusion and receive the government's diffusion subsidy $V_{e}$ and the benefits $W_{e}$ after diffusion; on the contrary, if the company does not carry out generic technology diffusion, they will pay a certain penalty $\operatorname{cost} F_{e}$ for not actively responding to the promotion of generic technology, and there will be a hidden loss $L_{e}$ due to technological lag.

Hypothesis 5. The abovementioned variables related to enterprises and governments will affect the strategic choices of enterprises and governments.

According to the significance of the above parameter variables, the game matrix of enterprises and government is constructed, as shown in Table 1 . Considering the $2 \times 2$ nonrepeated symmetric game and that the government can choose the policy support strategy randomly and independently, the government's policy support strength is taken as the value of $\mu_{1}\left(0 \leq \mu_{1} \leq 1\right)$. The larger the value, the higher the support strength. Also, the enterprise's participation in the generic technology diffusion strength is taken as the value of $\mu_{2}\left(0 \leq \mu_{2} \leq 1\right)$. The larger the value, the greater the diffusion intensity.

First of all, the expected return and the overall average expected return of companies choosing generic technology diffusion and nondiffusion are $\phi_{21}, \phi_{22}$, and $\bar{\phi}_{2}$. Then, we can obtain that

$$
\begin{aligned}
\phi_{21} & =x\left(S_{e}+W_{e}+V_{e}-C_{e}\right)+(1-x)\left(S_{e}+W_{e}-C_{e}\right), \\
\phi_{22} & =x\left(S_{e}-F_{e}-L_{e}-\mu_{2} C_{e}\right)+(1-x)\left(S_{e}-L_{e}-\mu_{2} C_{e}\right), \\
\bar{\phi}_{2} & =y \phi_{21}+(1-y) \phi_{22} .
\end{aligned}
$$


TABLE 1: Game payment matrix between government and enterprise.

\begin{tabular}{lccc}
\hline Income & & Enterprise $A$ & Nondiffusion $(\bar{e})$ \\
\hline Government G & Policy support $(g)$ & Diffusion $(e)$ & $\left(F_{e}-C_{g}-P_{g}, S_{e}-F_{e}-L_{e}-\mu_{2} C_{e}\right)$ \\
& Without policy support $(\bar{g})$ & $\left(V_{g}-C_{g}-V_{e}, S_{e}+W_{e}+V_{e}-C_{e}\right)$ & $\left(-\mu_{1} C_{q}-P_{q}, S_{e}-L_{e}-\mu_{2} C_{e}\right)$ \\
\hline
\end{tabular}

Therefore, the dynamic equation of enterprise strategy replication is as follows:

$$
\begin{aligned}
F(y) & =\frac{\mathrm{d} y}{\mathrm{~d} t}=y\left(\phi_{21}-\bar{\phi}_{2}\right)=y(1-y)\left(\phi_{21}-\phi_{22}\right) \\
& =y(1-y)\left[x\left(V_{e}+F_{e}\right)+\left(\mu_{2}-1\right) C_{e}+W_{e}+L_{e}\right] .
\end{aligned}
$$

In the same way, the expected return and the overall average expected return of the government providing policy support or not are $\phi_{11}, \phi_{12}$, and $\bar{\phi}_{1}$. Then, we can obtain that

$$
\begin{aligned}
& \phi_{11}=y\left(V_{g}-C_{g}-V_{e}\right)+(1-y)\left(F_{e}-C_{g}-P_{g}\right), \\
& \phi_{12}=y\left(V_{g}-\mu_{1} C_{g}\right)+(1-y)\left(-\mu_{1} C_{g}-P_{g}\right), \\
& \bar{\phi}_{1}=x \phi_{11}+(1-x) \phi_{12} .
\end{aligned}
$$

Therefore, the dynamic equation of government strategy replication is as follows:

$$
\begin{aligned}
F(x) & =\frac{\mathrm{d} x}{\mathrm{~d} t}=x\left(\phi_{11}-\bar{\phi}_{1}\right)=x(1-x)\left(\phi_{11}-\phi_{12}\right) \\
& =x(1-x)\left[-y\left(V_{e}+F_{e}\right)+F_{e}-\left(1-\mu_{1}\right) C_{g}\right] .
\end{aligned}
$$

From the abovementioned two equations, we can obtain the dynamic equation of replication of the generic technology diffusion of government and enterprises as

$$
\left\{\begin{array}{l}
\frac{\mathrm{d} x}{\mathrm{~d} t}=x(1-x)\left[-y\left(V_{e}+F_{e}\right)+F_{e}-\left(1-\mu_{1}\right) C_{g}\right], \\
\frac{\mathrm{d} y}{\mathrm{~d} t}=y(1-y)\left[x\left(V_{e}+F_{e}\right)+\left(\mu_{2}-1\right) C_{e}+W_{e}+L_{e}\right] .
\end{array}\right.
$$

\section{Model Analysis}

3.1. Evolutionary Analysis of Enterprise Strategy. When $F(y)=0, \quad y=\left(\left(1-\mu_{2}\right) C_{e}-W_{e}-L_{e}\right) /\left(V_{e}+F_{e}\right) \quad$ and $0 \leq\left(\left(\left(1-\mu_{2}\right) C_{e}-W_{e}-L_{e}\right) /\left(V_{e}+F_{e}\right)\right) \leq 1$. At this time, $y$ is in equilibrium. When $x \neq\left(\left(1-\mu_{2}\right) C_{e}-W_{e}-L_{e}\right) /\left(V_{e}+F_{e}\right)$, let $F(y)=0$, and we can obtain the equilibrium points of $F(y)$, which are $y=0$ and $y=1$.

Then, we can obtain the derivative of function (2) as

$$
F^{\prime}(y)=\frac{\mathrm{d} F(y)}{\mathrm{d} y}=(1-2 y)\left[x\left(V_{e}+F_{e}\right)+\left(\mu_{2}-1\right) C_{e}+W_{e}+L_{e}\right] .
$$

For $F^{\prime}(y)<0$, which is the requirement of the evolutionary stability strategy, two cases can be obtained and discussed as follows:
(1) When $\quad\left(1-\mu_{2}\right) C_{e}-W_{e}-L_{e}<0, \quad\left(\left(\left(1-\mu_{2}\right) C_{e}-\right.\right.$ $\left.\left.W_{e}-L_{e}\right) /\left(V_{e}+F_{e}\right)\right)<0$, and we always can obtain $\left(\left(\left(1-\mu_{2}\right) C_{e}-W_{e}-L_{e}\right) /\left(V_{e}+F_{e}\right)\right)<x \quad$ and $F^{\prime}(1)<0$. At this time, $y=1$ is an evolutionarily stable strategy. Then, $-\left(\mu_{2} C_{e}+L_{e}\right)<W_{e}-C_{e}$ can be deduced from $\left(1-\mu_{2}\right) C_{e}-W_{e}-L_{e}<0$. At this time, when the government adopts a policy support strategy with the horizontal coefficient higher than $\left(\left(1-\mu_{2}\right) C_{e}-W_{e}-L_{e}\right) /\left(V_{e}+F_{e}\right)$ and the enterprise's income from technology diffusion is higher than that from nondiffusion, the enterprise's diffusion strategy shall be an evolutionary equilibrium strategy.

(2) When $\left(1-\mu_{2}\right) C_{e}-W_{e}-L_{e}>0, \quad-\left(\mu_{2} C_{e}+L_{e}\right)>$ $W_{e}-C_{e}$, which means that the net income of the enterprise from the diffusion of generic technology is less than that without the diffusion of generic technology, and $\left(\left(\left(1-\mu_{2}\right) C_{e}-W_{e}-L_{e}\right) /\right.$ $\left.\left(V_{e}+F_{e}\right)\right)>0$; the following two situations can be obtained:

(a) When $\left(\left(\left(1-\mu_{2}\right) C_{e}-W_{e}-L_{e}\right) /\left(V_{e}+F_{e}\right)\right)>1$, $\left(\left(\left(1-\mu_{2}\right) C_{e}-W_{e}-L_{e}\right) /\left(V_{e}+F_{e}\right)\right)>x$. At this time, $F^{\prime}(0)<0$, and the evolutionary stability strategy is $y=0$. When the government adopts a policy support strategy with a level coefficient that is less than $\left(\left(1-\mu_{2}\right) C_{e}-W_{e}-L_{e}\right) /$ $\left(V_{e}+F_{e}\right)$, the enterprise shall not carry out generic technology diffusion as a stable equilibrium strategy.

(b) When

$0<\left(\left(\left(1-\mu_{2}\right) C_{e}-W_{e}-L_{e}\right) /\left(V_{e}+F_{e}\right)\right)<1$, there are still two situations to discuss. When $\left(\left(\left(1-\mu_{2}\right) C_{e}-W_{e}-L_{e}\right) /\left(V_{e}+F_{e}\right)\right)>x$, $F^{\prime}(0)<0$, the stable equilibrium point is $y=0$. When $\left(\left(\left(1-\mu_{2}\right) C_{e}-W_{e}-L_{e}\right) /\left(V_{e}+F_{e}\right)\right)<x$, $F^{\prime}(y)<0$, the stable equilibrium point is $y=1$.

3.2. Evolutionary Analysis of Government Strategy. When $F(x)=0, \quad y=\left(\left(F_{e}-\left(1-\mu_{1}\right) C_{g}\right) /\left(V_{e}+F_{e}\right)\right) \quad$ and $0 \leq\left(\left(F_{e}-\left(1-\mu_{1}\right) C_{g}\right) /\left(V_{e}+F_{e}\right)\right) \leq 1$, and $x$ is in equilibrium. When $y \neq\left(\left(F_{e}-\left(1-\mu_{1}\right) C_{g}\right) /\left(V_{e}+F_{e}\right)\right)$ and $F(x)=0$, the balance point of $F(x)$ is $x=0$ and $x=1$. From formula (4), we can obtain that $F^{\prime}(x)=((\mathrm{d} F(x)) / \mathrm{d} x)=$ $(1-2 x)\left[-y\left(V_{e}+F_{e}\right)+F_{e}-\left(1-\mu_{1}\right) C_{g}\right]$ and the requirement of the evolutionary stability strategy is $F^{\prime}(x)<0$. Then, there are the following two cases:

(1) When $F_{e}-\left(1-\mu_{1}\right) C_{g}<0,\left(\left(F_{e}-\left(1-\mu_{1}\right) C_{g}\right) /\left(V_{e}+\right.\right.$ $\left.\left.F_{e}\right)\right)<0$, and we have $\left(\left(F_{e}-\left(1-\mu_{1}\right) C_{g}\right) /\left(V_{e}+\right.\right.$ $\left.\left.F_{e}\right)\right)<y, F^{\prime}(0)<0$. At this time, $x=0$ indicates an evolutionarily stable strategy. In the case of $F_{e}-(1-$ 
$\left.\mu_{1}\right) C_{g}<0$ and $F_{e}<\left(1-\mu_{1}\right) C_{g}$, when the company adopts a generic technology diffusion strategy with the level coefficient greater than $y^{*}=\left(\left(F_{e}-\left(1-\mu_{1}\right) C_{g}\right) /\left(V_{e}+F_{e}\right)\right)$ and the government obtains more costs than income from policy support, the government does not carry out policy support, which is an evolutionary stable equilibrium strategy.

(2) When $F_{e}-\left(1-\mu_{1}\right) C_{g}>0,\left(\left(F_{e}-\left(1-\mu_{1}\right) C_{g}\right) /\left(V_{e}+\right.\right.$ $\left.\left.F_{e}\right)\right)>0$, and we have $\left(\left(F_{e}-\left(1-\mu_{1}\right) C_{g}\right) /\right.$ $\left.\left(V_{e}+F_{e}\right)\right)>y$ and $F^{\prime}(1)<0$. At this time, $x=1$ indicates an evolutionarily stable strategy. In the case of $F_{e}-\left(1-\mu_{1}\right) C_{g}>0$ and $F_{e}>\left(1-\mu_{1}\right) C_{g}$, when the company adopts a generic technology diffusion strategy with the level coefficient less than $y^{*}=\left(\left(F_{e}-\left(1-\mu_{1}\right) C_{g}\right) /\left(V_{e}+F_{e}\right)\right)$ and the government obtains more income than costs from policy support, the government's policy support is an evolutionary stable equilibrium strategy.

3.3. Evolutionary Analysis of Government and Enterprise Strategy Systems. Let $(\mathrm{d} x / \mathrm{d} t)=0$ and $(\mathrm{d} y / \mathrm{d} t)=0$, that is, $x(1-x)\left[-x\left(V_{e}+F_{e}\right)+F_{e}-\left(1-\mu_{1}\right) C_{g}\right]=0$ and $y(1-y)$ $\left[x\left(V_{e}+F_{e}\right)+\left(\mu_{2}-1\right) C_{e}+W_{e}+L_{e}\right]=0$. By solving the system of equations, we can obtain the duplicate dynamic equilibrium points $P\{(x, y) \mid 0 \leq x, y \leq 1\}$ in the plane, which are $E_{1}(0,0), E_{2}(1,0), E_{3}(1,1), E_{4}(0,1)$, and $E_{5}\left(x^{*}, y^{*}\right)$. And, $\quad x^{*}=\left(\left(\left(1-\mu_{2}\right) C_{e}-W_{e}-L_{e}\right) /\left(V_{e}+F_{e}\right)\right) \quad$ and $y^{*}=\left(\left(F_{e}-\left(1-\mu_{1}\right) C_{g}\right) /\left(V_{e}+F_{e}\right)\right)$.

Take the partial derivative of $F(x)$ and $F(y)$. Then, the Jacobian matrix can be obtained as

$$
\begin{aligned}
& J=\left[\begin{array}{ll}
\frac{\partial F(x)}{\partial x} & \frac{\partial F(x)}{\partial y} \\
\frac{\partial F(y)}{\partial x} & \frac{\partial F(y)}{\partial y}
\end{array}\right] \\
& =\left[\begin{array}{c}
(1-2 x)\left[-y\left(V_{e}+F_{e}\right)+F_{e}-\left(1-\mu_{1}\right) C_{g}\right] \\
y(1-y)\left(V_{e}+F_{e}\right)
\end{array}\right.
\end{aligned}
$$

The determinant of the matrix $J$ is as

$$
\begin{aligned}
\operatorname{Det} J= & (1-2 x)\left[-y\left(V_{e}+F_{e}\right)+F_{e}-\left(1-\mu_{1}\right) C_{g}\right](1-2 y) \\
& \cdot\left[x\left(V_{e}+F_{e}\right)+\left(\mu_{2}-1\right) C_{e}+W_{e}+L_{e}\right]+x y(1-x)(1-y)\left(V_{e}+F_{e}\right)^{2} .
\end{aligned}
$$

$$
\left.\begin{array}{c}
-x(1-x)\left(V_{e}+F_{e}\right) \\
(1-2 y)\left[x \cdot\left(V_{e}+F_{e}\right)+\left(\mu_{2}-1\right) \cdot C_{e}+W_{e}+L_{e}\right]
\end{array}\right] .
$$

The trace of the above matrix is as

$$
\begin{aligned}
\operatorname{Tr} J= & (1-2 x)\left[-y\left(V_{e}+F_{e}\right)+F_{e}-\left(1-\mu_{1}\right) C_{g}\right]+(1-2 y) \\
& \cdot\left[x\left(V_{e}+F_{e}\right)+\left(\mu_{2}-1\right) C_{e}+W_{e}+L_{e}\right] .
\end{aligned}
$$

Among them, the determinant and trace of the Jacobian matrix are less than 0 , which are the necessary and sufficient conditions for gradual stability in the dynamic process of system evolution. Then, the above five equilibrium points are brought into formulae (8) and (9), and the following results are obtained, as shown in Table 2.

In the results shown in the above table, $\left(\mu_{2}-1\right) C_{e}+$ $W_{e}+L_{e}$ is the net income difference between the technology diffusion and nondiffusion of enterprises when the government chooses not to provide policy support; $F_{e}-(1-$ $\left.\mu_{1}\right) C_{g}$ is the net income difference between the government's policy support and nonsupport; $V_{e}+F_{e}+\left(\mu_{2}-1\right) C_{e}+W_{e}+$ $L_{e}$ is the net income difference between the generic technology diffusion and nondiffusion of enterprises under the government's policy support; $V_{e}+\left(1-\mu_{1}\right) C_{g}$ is the cost difference between the government's policy support and nonsupport.

Since the costs paid by the government for policy support must be greater than the costs for not providing policy support, $V_{e}+\left(1-\mu_{1}\right) C_{g}$ is always greater than 0 . And, when the enterprise carries out generic technology diffusion and the government provides policy support, the income obtained by the enterprise, in this case, must be greater than the case that the government does not provide policy support, namely, $V_{e}+F_{e}+\left(\mu_{2}-1\right) C_{e}+W_{e}+L_{e}>$ $\left(\mu_{2}-1\right) C_{e}+W_{e}+L_{e}$. Through simple analysis, we can get the following six scenarios:

(1) When $F_{e}-\left(1-\mu_{1}\right) C_{g}>0$ and $\left(\mu_{2}-1\right) C_{e}+W_{e}+$ $L_{e}>0$, the stability analysis of the strategy system of the government and enterprise is obtained which is shown in Table 3.

It can be seen from Table 3 that $E_{2}(0,1)$ is ESS. In this case, the government shall choose not to provide 
TABle 2: Matrix determinants and traces of equilibrium points.

\begin{tabular}{|c|c|c|}
\hline Equilibrium point & Species & Results \\
\hline$E_{1}(0,0)$ & $\begin{array}{c}\text { DET } \\
\text { TR } \\
\end{array}$ & $\begin{array}{c}{\left[F_{e}-\left(1-\mu_{1}\right) C_{g}\right]\left[\left(\mu_{2}-1\right) C_{e}+W_{e}+L_{e}\right]} \\
{\left[F_{e}-\left(1-\mu_{1}\right) C_{q}\right]+\left[\left(\mu_{2}-1\right) C_{e}+W_{e}+L_{e}\right]}\end{array}$ \\
\hline$E_{2}(0,1)$ & $\begin{array}{c}\text { DET } \\
\text { TR }\end{array}$ & $\begin{array}{c}{\left[V_{e}+\left(1-\mu_{1}\right) C_{g}\right]\left[\left(\mu_{2}-1\right) C_{e}+W_{e}+L_{e}\right]} \\
-\left[V_{e}+\left(1-\mu_{1}\right) C_{g}\right]-\left[\left(\mu_{2}-1\right) C_{e}+W_{e}+L_{e}\right]\end{array}$ \\
\hline$E_{3}(1,0)$ & $\begin{array}{c}\text { DET } \\
\text { TR }\end{array}$ & $\begin{array}{c}-\left[F_{e}-\left(1-\mu_{1}\right) C_{g}\right]\left[V_{e}+F_{e}+\left(\mu_{2}-1\right) C_{e}+W_{e}+L_{e}\right] \\
-\left[F_{e}-\left(1-\mu_{1}\right) C_{q}\right]+\left[V_{e}+F_{e}+\left(\mu_{2}-1\right) C_{e}+W_{e}+L_{e}\right]\end{array}$ \\
\hline$E_{4}(1,1)$ & $\begin{array}{c}\text { DET } \\
\text { TR }\end{array}$ & $\begin{array}{c}-\left[V_{e}+\left(1-\mu_{1}\right) C_{g}\right]\left[V_{e}+F_{e}+\left(\mu_{2}-1\right) C_{e}+W_{e}+L_{e}\right] \\
{\left[V_{e}+\left(1-\mu_{1}\right) C_{g}\right]-\left[V_{e}+F_{e}+\left(\mu_{2}-1\right) C_{e}+W_{e}+L_{e}\right]}\end{array}$ \\
\hline$E_{5}\left(x^{*}, y^{*}\right)$ & $\begin{array}{c}\text { DET } \\
\text { TR }\end{array}$ & $-\left(\begin{array}{c}{\left[F_{e}-\left(1-\mu_{1}\right) C_{g}\right]\left[\left(\mu_{2}-1\right) C_{e}+W_{e}+L_{e}\right]} \\
{\left[V_{e}+F_{e}+\left(\mu_{2}-1\right) C_{e}+W_{e}+L_{e}\right]\left[V_{e}+\left(1-\mu_{1}\right) C_{g}\right]} \\
0\end{array}\right) /\left(V_{e}+F_{e}\right)^{2}$ \\
\hline
\end{tabular}

TABLE 3: Stability analysis of strategy system $(a)$ of the government and enterprise.

\begin{tabular}{lccc}
\hline Equilibrium point & DET & TR & Stability \\
\hline$E_{1}(0,0)$ & $>0$ & $>0$ & Unstable \\
$E_{2}(0,1)$ & $>0$ & $<0$ & ESS \\
$E_{3}(1,0)$ & $<0$ & Change & Saddle point \\
$E_{4}(1,1)$ & $<0$ & Change & Saddle point \\
$E_{5}\left(x^{*}, y^{*}\right)$ & $<0$ & 0 & Saddle point \\
\hline
\end{tabular}

policy support, and the enterprise shall choose to carry out generic technology diffusion.

(2) When $F_{e}-\left(1-\mu_{1}\right) C_{g}<0$ and $\left(\mu_{2}-1\right) C_{e}+W_{e}+$ $L_{e}>0$, the stability analysis of the strategy system of the government and enterprise is obtained which is shown in Table 4.

It can be seen from Table 4 that $E_{2}(0,1)$ is ESS. In this case, the government shall choose not to provide policy support, and the enterprise shall choose to carry out generic technology diffusion.

(3) When $F_{e}-\left(1-\mu_{1}\right) C_{g}<0,\left(\mu_{2}-1\right) C_{e}+W_{e}+L_{e}<0$, and $V_{e}+F_{e}+\left(\mu_{2}-1\right) C_{e}+W_{e}+L_{e}<0$, the stability analysis of the strategy system of the government and enterprise is obtained which is shown in Table 5.

It can be seen from Table 5 that $E_{1}(0,0)$ is ESS. In this case, the government shall choose not to provide policy support, and the enterprise shall choose not to carry out generic technology diffusion.

(4) When $F_{e}-\left(1-\mu_{1}\right) C_{g}>0,\left(\mu_{2}-1\right) C_{e}+W_{e}+L_{e}<0$, and $V_{e}+F_{e}+\left(\mu_{2}-1\right) C_{e}+W_{e}+L_{e}<0$, the stability analysis of the strategy system of the government and enterprise is obtained which is shown in Table 6 .

It can be seen from Table 6 that $E_{3}(1,0)$ is ESS. In this case, the government shall choose to provide policy support and the enterprise shall choose not to carry out generic technology diffusion.

(5) When $F_{e}-\left(1-\mu_{1}\right) C_{g}<0,\left(\mu_{2}-1\right) C_{e}+W_{e}+L_{e}<0$, and $V_{e}+F_{e}+\left(\mu_{2}-1\right) C_{e}+W_{e}+L_{e}>0$, the stability analysis of the strategy system of the government and enterprise is obtained which is shown in Table 7.

It can be seen from Table 7 that $E_{1}(0,0)$ is ESS. In this case, the government shall choose not to provide
TABLE 4: Stability analysis of strategy system $(b)$ of the government and enterprise.

\begin{tabular}{lccc}
\hline Equilibrium point & DET & TR & Stability \\
\hline$E_{1}(0,0)$ & $<0$ & Change & Saddle point \\
$E_{2}(0,1)$ & $>0$ & $<0$ & ESS \\
$E_{3}(1,0)$ & $>0$ & $>0$ & Unstable \\
$E_{4}(1,1)$ & $<0$ & Change & Saddle point \\
$E_{5}\left(x^{*}, y^{*}\right)$ & $>0$ & 0 & Saddle point \\
\hline
\end{tabular}

TABLE 5: Stability analysis of strategy system $(c)$ of the government and enterprise.

\begin{tabular}{lccc}
\hline Equilibrium point & DET & TR & Stability \\
\hline$E_{1}(0,0)$ & $>0$ & $<0$ & ESS \\
$E_{2}(0,1)$ & $<0$ & Change & Saddle point \\
$E_{3}(1,0)$ & $<0$ & Change & Saddle point \\
$E_{4}(1,1)$ & $>0$ & $>0$ & Unstable \\
$E_{5}\left(x^{*}, y^{*}\right)$ & $>0$ & 0 & Saddle point \\
\hline
\end{tabular}

TABLE 6: Stability analysis of strategy system $(d)$ of the government and enterprise.

\begin{tabular}{lccc}
\hline Equilibrium point & DET & TR & Stability \\
\hline$E_{1}(0,0)$ & $<0$ & Change & Saddle point \\
$E_{2}(0,1)$ & $<0$ & Change & Saddle point \\
$E_{3}(1,0)$ & $>0$ & $<0$ & ESS \\
$E_{4}(1,1)$ & $>0$ & $>0$ & Unstable \\
$E_{5}\left(x^{*}, y^{*}\right)$ & $<0$ & 0 & Saddle point \\
\hline
\end{tabular}

TABLE 7: Stability analysis of strategy system (e) of the government and enterprise.

\begin{tabular}{lccc}
\hline Equilibrium point & DET & TR & Stability \\
\hline$E_{1}(0,0)$ & $>0$ & $<0$ & ESS \\
$E_{2}(0,1)$ & $<0$ & Change & Saddle point \\
$E_{3}(1,0)$ & $>0$ & $>0$ & Unstable \\
$E_{4}(1,1)$ & $<0$ & Change & Saddle point \\
$E_{5}\left(x^{*}, y^{*}\right)$ & $<0$ & 0 & Saddle point \\
\hline
\end{tabular}

policy support, and the enterprise shall choose not to carry out generic technology diffusion.

(6) When $F_{e}-\left(1-\mu_{1}\right) C_{g}>0,\left(\mu_{2}-1\right) C_{e}+W_{e}+L_{e}<0$ and $V_{e}+F_{e}+\left(\mu_{2}-1\right) C_{e}+W_{e}+L_{e}>0$, the stability 
analysis of the strategy system of the government and enterprise is obtained which is shown in Table 8 .

It can be seen from Table 8 that there is no evolutionary stable strategy in this case.

In summary, the choices of the government and enterprise towards generic technology diffusion are shown in Table 9.

The dynamic game analysis on the choices of enterprises over generic technology diffusion is obtained, and we can get that the choices of enterprises over generic technology diffusion depend on whether $\left(\mu_{2}-1\right) C_{e}+W_{e}+L_{e}$ is greater than zero.

As shown in Table 9, whether or not the enterprises choose to carry out generic technology diffusion depends on the value of $\left(\mu_{2}-1\right) C_{e}+W_{e}+L_{e}$. When $\left(\mu_{2}-1\right) C_{e}+W_{e}+$ $L_{e}>0$ (see Scenario 1 and Scenario 2), the enterprises will choose to carry out generic technology diffusion. When $\left(\mu_{2}-1\right) C_{e}+W_{e}+L_{e}<0$ (see Scenario 3, 4, and 5), the enterprises will choose not to carry out generic technology diffusion.

Also, the value of $\left(\mu_{2}-1\right) C_{e}+W_{e}+L_{e}$ is determined by the following four variables: the investment of human and material resources selected by the enterprise for generic technology diffusion, that is, the cost $C_{e}$ of generic technology diffusion, the hidden loss $L_{e}$ of technology lag caused by nongeneric technology diffusion, the benefit $W_{e}$ from generic technology diffusion, and the intensity coefficient $\mu_{2}$ of generic technology diffusion.

Proposition 1. The cost of the diffusion of generic technology $C_{e}$, the government subsidy $V_{e}$, and the benefit $W_{e}$ will affect the evolution equilibrium result of generic technology diffusion.

That is, the lower the cost of generic technology diffusion, the greater the government subsidy and the greater the benefit from the diffusion, which will be more conducive to the realization of the equilibrium of generic technology diffusion.

Proposition 2. When the intensity coefficient $\mu_{2}$ of the generic technology diffusion of enterprises meets the value range $0 \leq \mu_{2} \leq 1$, the value of enterprise $y$ will increase steadily as the value of $\mu_{2}$.

That is, when an enterprise carries out generic technology diffusion, the intensity coefficient of generic technology diffusion of the enterprise will affect the enterprise's generic technology diffusion. When other conditions remain unchanged, the greater the value of $\mu_{2}$, the more $\left(\mu_{2}-1\right) C_{e}+W_{e}+L_{e}>0$ is established. That is, the intensity coefficient $\mu_{2}$ of generic technology diffusion of enterprises has a positive effect on generic technology diffusion.

Proposition 3. The value of $y$ for enterprises to carry out generic technology diffusion depends on the value of $x$ of whether the government chooses to provide policy support.
TABLE 8: Stability analysis of strategy system $(f)$ of the government and enterprise.

\begin{tabular}{lccc}
\hline Equilibrium point & DET & TR & Stability \\
\hline$E_{1}(0,0)$ & $<0$ & Change & Saddle point \\
$E_{2}(0,1)$ & $<0$ & Change & Saddle point \\
$E_{3}(1,0)$ & $<0$ & Change & Saddle point \\
$E_{4}(1,1)$ & $<0$ & Change & Saddle point \\
$E_{5}\left(x^{*}, y^{*}\right)$ & $>0$ & 0 & Saddle point \\
\hline
\end{tabular}

Take $\left(x^{*}, y^{*}\right)$ as the critical value of $(x, y)$, and when the initial state is $x^{*}<x, y=1$ is the stable point; when $x^{*}>x$, $y=0$ is the stable point.

That is, the choices of enterprises over generic technology diffusion will be affected by the government's attitude towards generic technology diffusion. When $x^{*}<x$, enterprises shall choose to carry out generic technology diffusion, but when $x^{*}>x$, enterprises shall choose not to carry out generic technology diffusion.

\section{Data Simulation and Analysis}

4.1. Data Simulation of Different Strategies of Government and Enterprises. In order to verify the research results, we use several key parameters such as special funds for the generic technology diffusion $C_{g}$, the cost of the generic technology diffusion of enterprises $C_{e}$, the policy support of the government $\mu_{1}\left(0 \leq \mu_{1} \leq 1\right)$, and the intensity of enterprises' participation in the generic technology diffusion $\mu_{2}$ for numerical analysis.

For the convenience of calculation, we assume that the initial probability of the government providing policy support $X$ is 0.4 and the initial probability of enterprises carrying out generic technology diffusion $Y$ is 0.6 , which are the initial points. The time $t$ is represented in the $x$-axis, and the probability of the government providing policy support $X$ and the probability of enterprises carrying out generic technology diffusion $Y$ are represented in the $y$-axis.

In this section, similar to the research method used in the literature $[11,22,23]$, an enumeration method is used to analyze six evolutionary equilibrium strategies under different decisions made by the government and enterprises:

(1) When $F_{e}-\left(1-\mu_{1}\right) C_{g}>0$ and $\left(\mu_{2}-1\right) C_{e}+W_{e}+$ $L_{e}>0$, suppose $V_{e}=4, F_{e}=4, C_{e}=5, C_{g}=9$, $W_{e}=2, L_{e}=2, \mu_{2}=0.6$, and $\mu_{1}=0.6$. Then, we get Figure 1. It can be known from it that $E_{2}(0,1)$ in Table 3 is ESS, and the corresponding strategy is without policy support and diffusion. And, from the assumed parameters in Figure 1, we can get that when the benefits obtained by enterprises from generic technology diffusion are greater than that from not performing generic technology diffusion, and the enterprises tend to actively carry out generic technology diffusion. In this case, the government tends to ease its guidance on the diffusion of generic technology to save costs.

(2) When $F_{e}-\left(1-\mu_{1}\right) C_{g}<0$ and $\left(\mu_{2}-1\right) C_{e}+W_{e}+$ $L_{e}>0$, suppose $V_{e}=4, F_{e}=4, C_{e}=5, C_{g}=9$, 
TABLE 9: Government and enterprise strategy choices.

\begin{tabular}{lcccc}
\hline Serial number & $F_{e}-\left(1-\mu_{1}\right) C_{g}$ & $\left(\mu_{2}-1\right) C_{e}+W_{e}+L_{e}$ & $V_{e}+F_{e}+\left(\mu_{2}-1\right) C_{e}+W_{e}+L_{e}$ & Stability strategy \\
\hline 1 & $>0$ & $>0$ & $>0$ & $(-,+)$ \\
2 & $<0$ & $>0$ & $>0$ & $(-,+)$ \\
3 & $<0$ & $<0$ & $<0$ & $(-,-)$ \\
4 & $>0$ & $<0$ & $>0$ & $(+,-)$ \\
5 & $<0$ & $<0$ & $>0$ & $(-,-)$ \\
6 & $>0$ & $<0$ & No ESS \\
\hline
\end{tabular}

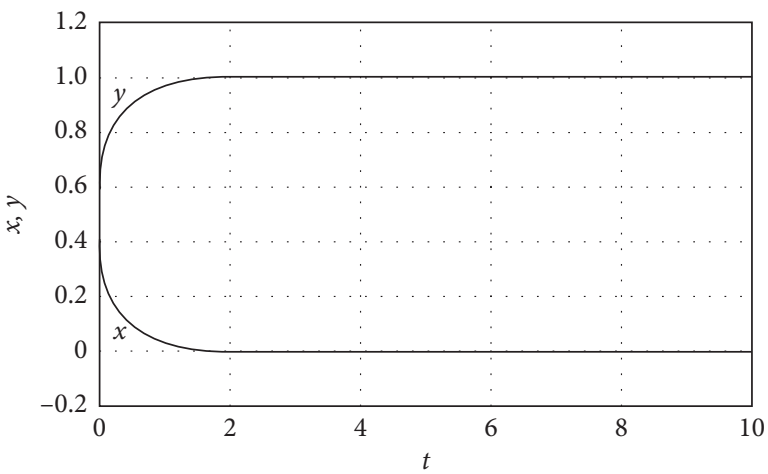

Figure 1: Dynamic evolution of government and enterprise strategy $(a)$.

$W_{e}=2, L_{e}=2, \mu_{2}=0.3$, and $\mu_{1}=0.5$. Then, we get Figure 2. It can be known from it that $E_{2}(0,1)$ in Table 4 is ESS, and the corresponding strategy is without policy support and diffusion. And, from the assumptions in Figure 2, we can obtain that whether enterprises choose to carry out generic technology diffusion is affected by the penalty costs to some degree, and when the government takes regulatory measures, generic technology diffusion will have a significant effect.

(3) When $V_{e}+F_{e}+\left(\mu_{2}-1\right) C_{e}+W_{e}+L_{e}<0, \quad\left(\mu_{2}-1\right)$ $C_{e}+W_{e}+L_{e}<0$, and $F_{e}-\left(1-\mu_{1}\right) C_{g}<0$, suppose $V_{e}=2, F_{e}=2, C_{e}=7, C_{g}=9, \quad W_{e}=1, L_{e}=1$, $\mu_{2}=0.1$, and $\mu_{1}=0.5$. Then, we get Figure 3. It can be known from it that $E_{1}(0,0)$ in Table 5 is ESS, and the corresponding strategy is without policy support and no diffusion. And, from the assumptions in Figure 3, we can obtain that if the government does not provide policy support for generic technology diffusion, enterprises will choose not to carry out generic technology diffusion because more income can be obtained by doing so than carrying out generic technology diffusion.

(4) When $\left(\mu_{2}-1\right) C_{e}+W_{e}+L_{e}<0, V_{e}+F_{e}+\left(\mu_{2}-1\right)$ $C_{e}+W_{e}+L_{e}<0$, and $F_{e}-\left(1-\mu_{1}\right) C_{g}>0$, suppose $V_{e}=1, F_{e}=3, C_{e}=7, C_{g}=9, \quad W_{e}=1, L_{e}=1$, $\mu_{2}=0.1$, and $\mu_{1}=0.7$. Then, we get Figure 4 . It can be known from it that $E_{3}(1,0)$ in Table 6 is ESS, and the corresponding strategy is policy support and no diffusion. And, from the assumptions in Figure 4, we can obtain that the enthusiasm of enterprises for generic technology diffusion will decline because the

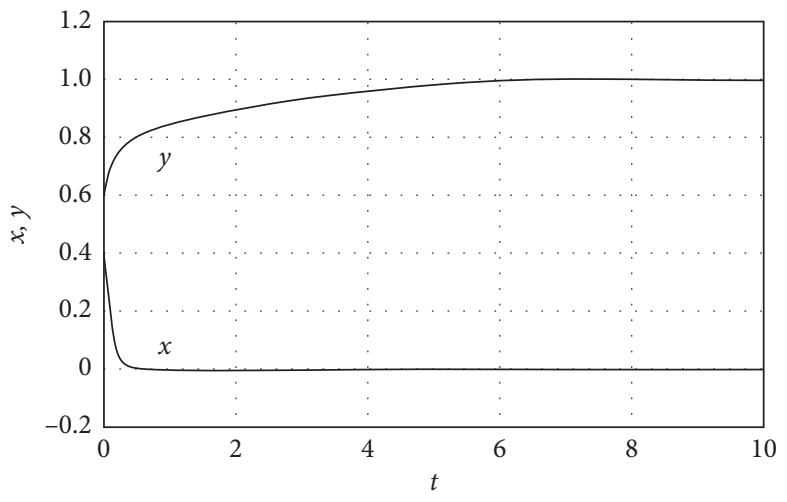

FIgURE 2: Dynamic evolution of government and enterprise strategy $(b)$.

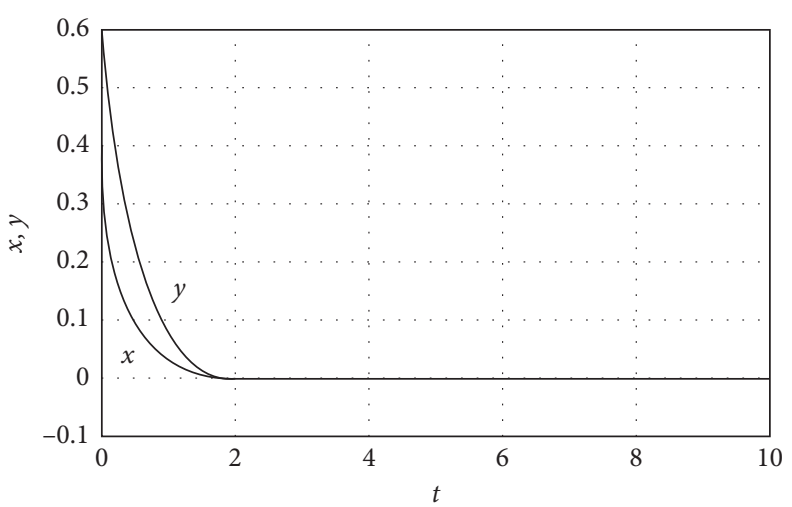

FIGURE 3: Dynamic evolution of government and enterprise strategy $(c)$.

income generated by performing generic technology diffusion is not higher than that generated by not performing it, while the government will actively provide policy support because the income generated by providing policy support are higher than that generated by not providing policy support.

(5) When $\left(\mu_{2}-1\right) C_{e}+W_{e}+L_{e}<0, V_{e}+F_{e}+\left(\mu_{2}-1\right)$ $C_{e}+W_{e}+L_{e}>0$, and $F_{e}-\left(1-\mu_{1}\right) C_{g}<0$, suppose $V_{e}=4, F_{e}=4, C_{e}=5, C_{g}=9, \quad W_{e}=2, L_{e}=1$, $\mu_{2}=0.3$, and $\mu_{1}=0.5$. Then, we get Figure 5. It can be known from it that $E_{1}(0,0)$ in Table 7 is ESS, and the corresponding strategy is without policy support and no diffusion. And, from the assumptions in Figure 5, we can obtain that enterprises tend to carry 


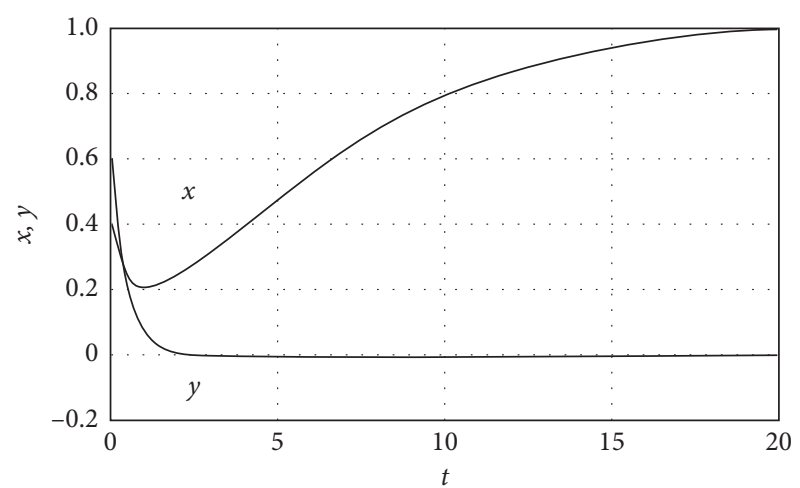

Figure 4: Dynamic evolution of government and enterprise strategy $(d)$.

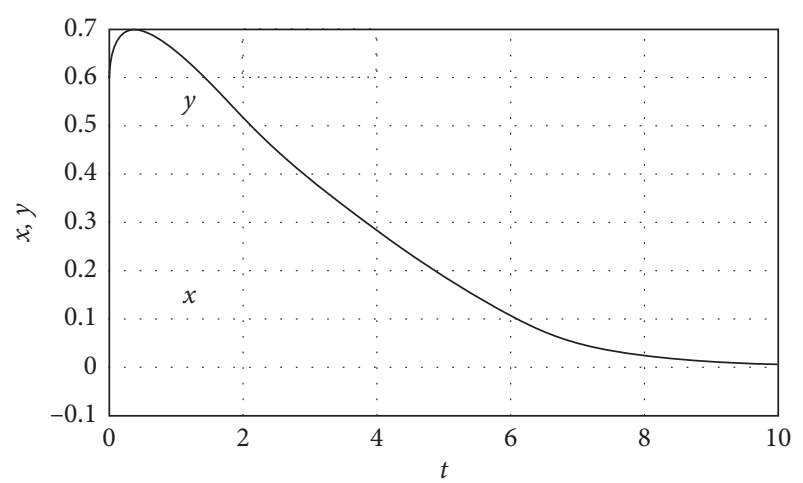

Figure 5: Dynamic evolution of government and enterprise strategy $(e)$.

out generic technology diffusion when the government provides policy support, and governmental incentives and subsidies will boost the enthusiasm of enterprises towards generic technology diffusion.

(6) When $V_{e}+F_{e}+\left(\mu_{2}-1\right) C_{e}+W_{e}+L_{e}>0$, $\left(\mu_{2}-1\right)$ $C_{e}+W_{e}+L_{e}<0$, and $F_{e}-\left(1-\mu_{1}\right) C_{g}>0$, suppose $V_{e}=4, F_{e}=4, C_{e}=8, C_{g}=7, W_{e}=2, L_{e}=2$, $\mu_{2}=0.1$, and $\mu_{1}=0.6$. Then, we get Figure 6 . It can be known from it that there is no evolutionary stability strategy in Table 8 . Also, there are two balance points $y=0$ and $y=1$ for the enterprise replicator dynamic equation $F(y)=0$, respectively. When the initial state is $x^{*}<x, y=1$ is the stable point; when $x^{*}>x, y=0$ is the stable point. There are two balance points $x=0$ and $x=1$ for the government's replicator dynamic equation $F(x)=0$. When the initial state is $y^{*}<y, x=0$ is the stable point; when the initial state is $y^{*}>y, x=1$ is the stable point. In this case, the strategies of the government and enterprises are determined by the critical value $\left(x^{*}, y^{*}\right)$ of the initial state. To find the critical value, we set $(x, y)$ as $(0.8,0.2),(0.6,0.4)$, $(0.5,0.5),(0.3,0.7)$, and $(0.1,0.9)$, respectively, and obtain the following figure through numerical simulation.

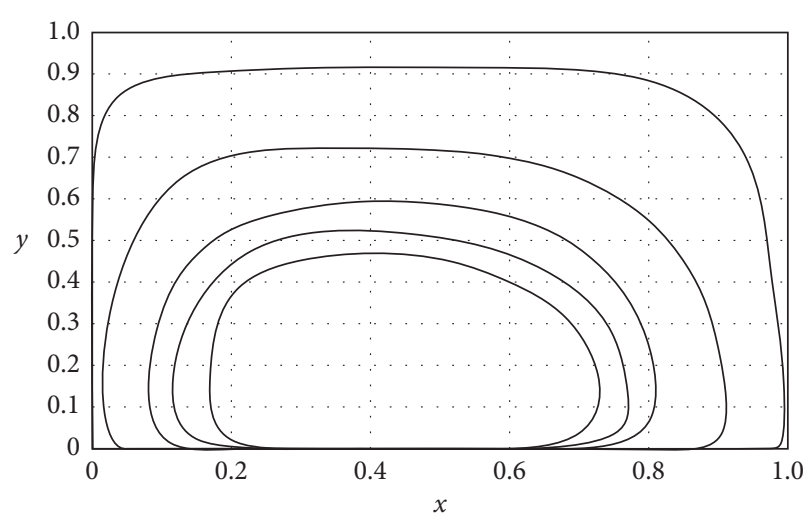

FIGURE 6: Dynamic evolution of government and enterprise strategy $(f)$.

4.2. Data Simulation Results. Whether an enterprise chooses to carry out generic technology diffusion is affected by the costs incurred, the degree of participation in the process of generic technology diffusion, and the income generated in the process.

According to the above data simulation analysis, we can verify Proposition 1 . The lower the cost of enterprise generic technology diffusion $C_{e}$, the greater the government diffusion subsidy received from the diffusion $V_{e}$, and the greater the income generated from the diffusion $W_{e}$, and thus, enterprises are more likely to carry out generic technology diffusion.

According to the numerical simulation analysis of Scenario 1 and 2, we can verify Proposition 2 . The intensity coefficient of enterprise generic technology diffusion will have a positive impact on the decision-making of enterprises over generic technology diffusion, that is, the two are positively correlated. When $\mu_{2}=0.3$, enterprises' strategic choice for generic technology diffusion lags behind the case when $\mu_{2}=0.6$.

According to the numerical simulation analysis of Scenario 6, we can verify Proposition 3. It can be seen that the evolutionary trajectory of the generic technology diffusion strategy of government and enterprises is circular, and the critical point is $x=0.4$ and $y=0.15$. When $x>0.4, y$ tends to 1 , which means that the enterprises choose to carry out generic technology diffusion; when $x<0.4, y$ tends to 0 , which means that the enterprises choose not to carry out generic technology diffusion.

To sum up, the more the costs incurred by generic technology diffusion, the smaller the probability of the subject carrying out generic technology diffusion. Incentive policies provided by the government will have a significant positive effect on the company's willingness to carry out generic technology diffusion, thereby improving the effect of generic technology diffusion. The participation of the government and enterprises affects the strategy choice and the effect of generic technology diffusion. The net income generated from generic technology diffusion also affects the enterprises' choice of generic technology diffusion strategy. When the income generated by the enterprises from performing generic technology diffusion is always greater than 
that from not performing it, the enterprises will choose to carry out generic technology diffusion regardless of whether the government provides policy support or not.

\section{Relevant Conclusions and Suggestions}

5.1. Relevant Conclusions. Based on a great amount of literature at home and abroad, this paper defines the subject of generic technology diffusion as enterprise and government and analyzes the selection of generic technology diffusion strategy for enterprises and government based on evolutionary game theory. Then, the results and influencing factors in different cases are explored and refined, and numerical simulation analysis is conducted to summarize and analyze the factors influencing generic technology diffusion. Finally, the following conclusions are obtained.

There are two factors that affect the diffusion of generic technology, which are the strategy choices of government and enterprises, respectively. Whether the government chooses to provide policy support for the diffusion of generic technology will have an impact on the evolution equilibrium of the diffusion of generic technology. Also, whether enterprises choose to carry out generic technology diffusion can greatly affect the extent of generic technology diffusion. The enthusiasm of enterprises towards generic technology diffusion is mainly influenced by three factors, that is, the cost of generic technology diffusion, the government subsidy, and the income generated from the diffusion. For enterprises, if they choose to participate in the diffusion of generic technology, the net income shall be higher than that when they do not participate. In doing so, the evolution equilibrium of generic technology diffusion can be better achieved.

In the process of generic technology diffusion, the strength coefficient of generic technology diffusion affects the decision-making of diffusion time. The larger the strength coefficient is, the easier it is to realize the evolution equilibrium of generic technology diffusion.

5.2. Improvement Suggestions from the Government Perspective. Government plays a guiding role in the process of diffusion, which is generally achieved by macrocontrol. As mentioned earlier in this paper, the fundamental and public features of generic technology also indicate that generic technology cannot be a personal thing or a purely private item. The features of such quasi-public products affirm the macrobenefits of policy support at the root. For the promotion of generic technology diffusion, the following countermeasures and suggestions are made for the government.

First of all, the government can build an information platform for the diffusion of generic technology. The diffusion of generic technology is not just a unilateral activity. It requires the cooperation of both the supplier and the recipient of the technology. Given this, the exchange and communication of information between the supplier and the recipient are extremely important. The government can establish relevant policy provisions and urge relevant departments to establish an information platform such as an agency or social organization. Based on such an information platform, professional data and information analysis can be conducted to strengthen the quality of information so as to promote cooperation and mutual assistance between the supplier and the recipient.

Secondly, the government can formulate relevant fiscal and tax incentives and punishment policies. As can be seen from this study, the costs of generic technology diffusion affect the results of generic technology diffusion. Also, the adjustment of the government's fiscal and taxation policies can have little impact on the costs of generic technology diffusion of enterprises, thereby influencing the attitudes of enterprises towards generic technology diffusion. Considering this, the government can develop some incentive and reward policies based on fiscal and tax policies with the aim of strengthening the determination of enterprises to carry out generic technology diffusion. For example, the government can grant subsidies and rewards or reduce taxes for the enterprises performing generic technology diffusion based on the attributes of generic technology or even punish those that do not carry out generic technology diffusion. The aim is to take full advantage of "the invisible hand of the market" to reduce the cost of generic technology diffusion and increase the benefits obtained after generic technology diffusion. In this way, the enthusiasm of various companies to carry out generic technology diffusion can be raised, and thus, the overall development of generic technology diffusion can be promoted.

Last but not least, the government can encourage the innovation and R \& D of generic technology. The diffusion of a generic technology is related to not only the diffuser of the generic technology, its broadcasting channels, and the degree of policy support but also the generic technology itself. The prerequisite for the rapid diffusion of new technology is that this generic technology is simple to operate, not complex, and has basic technical requirements. In this way, both high-level professional recipients and most of the adopters with basic capabilities can introduce this technology. As a result, a high income can be generated from generic technology diffusion.

\subsection{Improvement Suggestions from the Enterprise Perspective.} Enterprises attach great importance to the benefits obtained from the diffusion and applications of generic technology. The diffusion of generic technology requires enterprises to have the ability to introduce and use the generic technology. From the perspective of the supply side, the technical capability of the enterprises is positively related to the economic benefits of generic technology diffusion. Therefore, the improvement of the enterprises themselves is also of great significance to the promotion of the diffusion of generic technology. In view of this, suggestions from the following two aspects are given to the enterprises.

First, enterprises should pay attention to the quality of internal talents and strengthen diffusion intensity. If the enterprises want to improve their capabilities to innovate, research, and use generic technology, they need to improve 
the capabilities of internal employees to use the generic technology. This requires changes and improvements in the talent structure of the enterprises. Furthermore, the enterprises can seek cooperation with major universities to prepare for the cultivation of outstanding employees. According to the features of different generic technologies, the enterprises can cultivate talents in universities in a targeted manner. In addition, the enterprises can invest in establishing talent training bases and offer enterprise scholarships to encourage university students to serve enterprises, thereby improving the talent structure of enterprises and increasing the benefits of generic technology diffusion.

Second, enterprises should maintain their technological level and reduce the costs of diffusion. If an enterprise has a negative and conservative attitude towards the development of society in a long term, the enterprise will pay a high price for the technology update, and the costs will be more as they introduce new generic technology, resulting in higher costs of generic technology diffusion. For this reason, the enterprises should actively abandon old technologies and introduce new technologies, so as to prevent the enterprises from being lost in a state of technological backwardness for a long time. In this way, the enterprises can seize the development opportunity as the diffusion of generic technology approaches so that the costs of generic technology diffusion can be reduced.

\section{Data Availability}

The data used to support the findings of this study are included within the article.

\section{Conflicts of Interest}

The authors declare that they have no conflicts of interest.

\section{Acknowledgments}

This study was supported by General Project of Philosophy and Social Sciences Planning in Anhui Province (Grant no. AHSKY2019D022), Youth Project of Natural Science Foundation of Anhui Province (Grant no. 2008085QG346), Anhui Province 2020 Excellent Talents Cultivation Project (Grant no. gxgwfx2020006), National Social Science Foundation of China (Grant no. 16BGL201), and Pre-Research Project of National Natural Science Foundation of China (Grant no. 2019yyzr07).

\section{References}

[1] Li Hui and Y. Nie, "A review of the research on the role of government in the development of generic technology innovation," Science and Technology Management Research, vol. 38, no. 17, pp. 88-92, 2018.

[2] J. Li and Q. Deng, "Multiple failures in the supply and diffusion of industrial common technologies," Science of Science and Management of Science and Technology, vol. 32, no. 7, pp. 5-10, 2011.
[3] Q.. Zou, "The concept and characteristics of common technology diffusion," Science and Technology Management Research, vol. 30, no. 19, pp. 142-145, 2010.

[4] Q.. Zou, "The components of common technology diffusion," Science and Technology Progress and Policy, vol. 28, no. 15, pp. 15-17, 2011.

[5] K. Khan, Z. H. Pathan, S. Hussain, Z. Latif, and W. Lei, "Factors affecting diffusion and adoption of information and communication technology among rural users in Khyber Pakhtunkhwa Province, Pakistan," International Journal of Information Technology and Management, vol. 1, no. 1, pp. 1-10, 2016.

[6] X. Zhang, S. Fan, and X. Cai, "The path of technology diffusion: which neighbors to learn from?" Contemporary Economic Policy, vol. 20, no. 4, pp. 470-478, 2002.

[7] J. Song, C. Xing, and H. Li, "Weighted local world network organization technology diffusion model and simulation analysis," Journal of Management Engineering, vol. 29, no. 1, pp. 149-155, 2015.

[8] Y. Zhou, "Analysis and empirical research on the influencing factors of generic enabling technology diffusion in the upgrade period of manufacturing paradigm," China Soft Science, vol. 12, pp. 19-32, 2018.

[9] Y. Ma, X. Su, and Y. Zhao, "Evolutionary game analysis of industrial generic technology diffusion," Control Theory and Application, vol. 36, no. 1, pp. 22-31, 2019.

[10] J. Liu, "Study on diffusion of human resource technology in Guizhou Province," The Frontiers of Society, Science and Technology, vol. 1, no. 8, pp. 20-28, 2019.

[11] Y. Zheng, B. Yang, and L. Wang, "Research on the evolution and multiple failures of industrial common technology R \& D behavior," Scientific Research Management, vol. 40, no. 5, pp. 164-174, 2019.

[12] Y. Zhang and H. Ling, "The "blind spot" dilemma of common technology supply for small and medium-sized enterprises and its solution: a case study," Scientific Research Management, vol. 40, no. 8, pp. 215-223, 2019.

[13] W. Niu, X. Chen, and H. Shen, "Optimal service decision of competitive retailers with service spillover effect," Journal of Systems Engineering, vol. 35, no. 2, pp. 222-231, 2020.

[14] G. Tassey, "Modeling and measuring the economic roles of technology infrastructure," Economics of Innovation and New Technology, vol. 17, no. 7, pp. 617-630, 2008.

[15] Q.. Zou, "Government behavior in the diffusion of common technology," Chinese Administration, vol. 2, pp. 66-68, 2008.

[16] J. Li, "Mode selection of supply and diffusion of common technology," Science of Science and Management of Science and Technology, vol. 32, no. 10, pp. 5-12, 2011.

[17] C. Wei and Z. Li, "Government roles in the industrial generic technology innovation research," Advances in Social Science, Education and Humanities Research, vol. 72, pp. 48-52, 2017.

[18] L. Zhao, J. Sun, and H. Zhang, "Research on technology sharing behavior of military-civilian integrated collaborative innovation system based on differential game," Journal of Management Engineering, vol. 31, no. 3, pp. 183-191, 2017.

[19] Y. Zheng, B. Yang, and L. Wang, "The evolution of industry common technology diffusion and its dynamic mechanism," Forum on Science and Technology in China, vol. 5, pp. 26-67, 2019.

[20] M. Xia and X. Deng, "An analysis of the optimal strength of the government's role in the diffusion of industrial common technology: a transformation-based Bass model," Journal of Beijing Institute of Technology, vol. 21, no. 2, pp. 78-86, 2019. 
[21] X. Yang, "Analysis of enterprise behavior tendency and technology spillover of multinational corporations," Journal of Systems Engineering, vol. 34, no. 4, pp. 445-458, 2019.

[22] G. Srivastava and P. R. Srivastava, "Impact of information technology on information search channel selection for consumers," Journal of Organizational and End User Computing, vol. 30, no. 3, pp. 63-80, 2018.

[23] L. Fabisiak, "Web service usability analysis based on user preferences," Journal of Organizational and End User Computing, vol. 30, no. 4, pp. 1-13, 2018. 